\title{
Use of herbal medicine during pregnancy and attitudes of pregnant women in Jos, Nigeria
}

\author{
Dalen G. DAFAM ${ }^{1 *}$, Adama DENOU ${ }^{1,3}$, Agnes IDOKO ${ }^{1}$, Nanloh S. JIMAM², Victoria A. \\ OKWORI $^{1}$, Temitayo L. OHEMU ${ }^{1}$, Thomas P. YAKUBU ${ }^{1}$ and Shalkur DAVID ${ }^{2}$ \\ ${ }^{I}$ Department of Pharmacognosy and Traditional Medicine; ${ }^{2}$ Department of Clinical Pharmacy and Pharmacy \\ Practice, Faculty of Pharmaceutical Sciences, University of Jos, P. M. B. 2084, Jos. Nigeria \\ ${ }^{3}$ Département des Sciences Pharmaceutiques, Faculté de Pharmacie, Université des Sciences, des Techniques et des \\ Technologies de Bamako, BP 1805, Bamako. Mali.
}

Received $28^{\text {th }}$ February 2020; Accepted $5^{\text {th }}$ October 2020

\begin{abstract}
Herbal medicines have been used for disease prevention and treatment for both humans and animals worldwide. The present study was designed to determine the herbs used during pregnancy in Jos and to evaluate attitudes of pregnant women. The survey was carried out in antenatal clinics. Information was obtained from pregnant women (17-60 years) through both informal, unstructured conversations and the use of structured questionnaire. Botanical data were focused on the name and part of the herbs or plant used during pregnancy including herbs, herbal preparations and finished products having medicinal properties. In total, 300 pregnant women were enrolled for this study. The respondents were farmers $(33.3 \%)$, housewives $(26.7 \%)$ and students $(23.3 \%)$. The most commonly used herbs were, garlic $(16.7$ $\%$ ), pawpaw (13.6 \%), ginger (13.0 \%) and Moringa (8.0\%). Among the parts, bulb was the most used (16.7 \%) followed by fruits $(14 \%)$. The most common reasons for the use were: herbal medicine is more effective than conventional medicine for some medications (20\%) and more easily accessed than conventional medicine (20\%). Most of the women were advised by family (31.3\%) and believed herbs had fewer side effects. The findings revealed their knowledge on medicinal plants. The women used one or more herbal medicine during pregnancy.
\end{abstract}

Keywords: Pregnant women; Herbal medicine; Medicinal plants; Jos; Nigeria

\section{INTRODUCTION}

Herbal medicines include herbs, herbal preparations and finished products that contain as active ingredients parts of plants or other plant materials or combinations perceived to have therapeutic benefits [1]. About $80 \%$ of the populations worldwide use a variety of traditional medicines including herbal medicine, for the diagnosis, prevention and treatment of illnesses, and for the improvement of general wellbeing [2]. Herbal medicine has been used for disease prevention and treating ailments worldwide. It is known that between $65 \%$ and $85 \%$ of the world population used herbal medicine as their primary form of health care [2]. Pregnancy is a condition associated with immense physiological alterations resulting in problems, including nausea, vomiting, constipation, and heartburn. Pregnancy is a special physiological condition where drug treatment presents a special concern because the physiology of pregnancy

*Correspondence. E-mail: dalendafam@gmail.com Tel: +234-8036127616.

ISSN 0189-8442

2021. Published by Faculty of Pharmaceutical Sciences, University of Jos, Nigeria. Under Creative Commons Attribution-Non-Commercial 4.0 International License. https://creativecommons.org/licenses/by-nc/4.0/ 
affects the pharmacokinetics of medications used and certain medications can reach the fetus and cause harm. Total avoidance of pharmacological treatment in pregnancy is not possible and can be dangerous because some women enter pregnancy with medical conditions that require ongoing and episodic treatment (e.g. asthma, epilepsy, hypertension.). Also during pregnancy new medical problems can develop and old ones can be exacerbated (e.g. migraine, headache) requiring pharmacological therapy. The fact that certain drugs given during pregnancy may prove harmful to the unborn child is one of the classical problems in medical treatment [3]. These conditions usually result in pregnant women self-medicating using over the counter (OTC) medications or herbs [4].

In pregnancy, mothers and doctors are concerned about all medications including herbal medicine. Herb use during pregnancy is common across regions and countries. The prevalence of herbal medicine use during pregnancy ranges from 12 to $82.3 \%$ [5]. A multinational study conducted in different countries also showed that $28.9 \%$ of pregnant women used herbal medicine during pregnancy [6]. A literature review from the Middle East revealed that up to $82.2 \%$ of the women used herbal medicine at some point during pregnancy. In Australia, $36 \%$ of the women took at least one herbal medicine during pregnancy [8]. Studies done in Africa showed that the prevalence of herbal medicine use during pregnancy was $12 \%$ to $73.1 \%$ [9]. The most commonly consumed herbal medicine during pregnancy include; ginger, cranberry, valerian, raspberry leaf, [7]. Eucalyptus, tenaadam (Rutachalepensis), damakees (Ocimum lamiifolium), palm kernel oil, bitter kola and dogonyaro (Azadirachta indica) are also other herbal medicine used during pregnancy [10].

There is crucial need for research into these medicinal plants or herbs to know the part used reasons for use and to know if the herbal medicine is more effective than conventional medicine and its safety during pregnancy. The current study aimed at determining the attitudes, knowledge and herbs used during pregnancy in Jos North and South Local Government Areas of Plateau state.

\section{EXPERIMENTAL METHODS}

Study area. This study was carried out in Jos North and South Local Government Areas of Plateau state, Nigeria (Figure 1). Jos North Local Government Area of Plateau State is one of its seventeen Local Government Areas and its main metropolis. It extends over an area of $291 \mathrm{~km}^{2}$ with a total population of 429,300 , projected from 2006 National Population and housing Census. Jos South is also a Local Government Area of Plateau State. Its headquarters is the town of Bukuru at $9^{\circ} 48^{\prime} 00$ $\mathrm{N} 8^{\circ} 52^{\prime} 00 \mathrm{E}$. It has an area of $510 \mathrm{~km}^{2}$ and a population of 306,716 at the 2006 census. The survey was done in hospitals, one on one meeting of pregnant women and primary health clinics where pregnant women go for antenatal and regular checkups. Hospitals and primary health care centers visited were as follows: Plateau Specialist Hospital, Bingham University Teaching Hospital, Rayfield primary health clinics, Angwan Rogo primary health clinic and Mary-sol specialist hospital.

Respondents. Pregnant women were considered to be the best source of information for this study. Field work was carried out in antenatal clinics and pregnant women attending antenatal within Jos North and South local government areas of Plateau State, Nigeria. Contact and interaction with the pregnant women were facilitated by the nurses in charge of the antenatal clinics within the study areas. The respondents were grouped between ages of 17 to 60 years. Prior informed consent from the informants was obtained before commencing the survey. Information was obtained through both informal, unstructured conversations and the use of 
structured questionnaires. The informal open discussion provided the opportunity for pregnant women to talk about their experience and to provide as much detail as they wished. This flexible approach also eliminated the pressure to provide answers to rigid questions, which might have led to artificial responses, given purely to satisfy the researcher. The pregnant women gave information relating to the identification of plants, their medicinal uses, parts used, doses for the preparation and comparison between orthodox and traditional medicine.

\section{RESULTS}

Demographic data. The demographical data are given in table 1 . A total of 300 women were interviewed during the survey. Most of the respondents were between 17 to 30 years $(59.7$ $\%)$ followed by those $31-40$ years old $(30.0 \%)$. Most of the interviewed women were farmers (33.3\%) and housewives (26.7\%). Most of the respondents were not formally educated (40 $\%$ ) while $23.3 \%$ attended higher educational institutions.

Ethnobotanical data. The majority of the pregnant women used herbal medicine during the first trimester of their pregnancy $(30 \%)$ and the use decreased to $18.6-4.0 \%$ in the second and third trimester respectively (Table 2 ). Those who stayed away from any form of herbal medication is represented by $47.3 \%$. By talking about the plants used, nine species belonging to nine families were recorded (Table 3). These plants are used for several indications of pregnancy such as increasing immunity, nausea, morning sickness, stomach discomfort, preventing gestation diabetes, stretch mark, stress and anxiety (Table 4). The most commonly used plants were Allium sativum (Garlic) and Carica papaya (Pawpaw) with $16.7 \%$ and $13.6 \%$ respectively followed by Zingiber officinale (Ginger) and Moringa oleifera (Moringa) with $13.0 \%$ and $8.0 \%$ respectively (Table 4). Among the plant parts used, the bulb and the fruit were most represented by $16.7 \%$ and $14.3 \%$ respectively (Table 5). The majority of the preparations or recipes were blended $(15.7 \%)$. The preparations are mainly used for pain, morning sickness, stretch mark, stomach discomfort, headache, immunity, blood pressure control, cold and flu (Table 6). The literature revealed that these medicinal plants contain some active constituents which support their use for the above mentioned ailments among pregnant women (Table 7).

Women's sources of advice for the treatment of ailments during pregnancy. Use of herbal medicine was most commonly initiated after recommendations from family $(31.3 \%)$ and other pregnant women $(26.7 \%)$. Only $1 \%$ of the respondents got advice from health professionals (pharmacists) (Table 8).

Women's attitudes. The reasons for using herbal medicine are noted in table 9 . The study showed that only $5 \%$ of the pregnant women thought the herbal medicine is more effective than conventional medicine. Among the respondents, $20 \%$ reported that herbal medicine more effective than conventional medicine for some medications. Only $5 \%$ found herbal medicine together with conventional medicine more effective. The reason of $6.6 \%$ for using herbal medicine was that herbal medicine has fewer side effects than conventional medicine. Among the informants, $20 \%$ reported that herbal medicine is more easily accessed than conventional medicine. The reason of $6.6 \%$ of the users was that herbal medicine is less expensive than conventional medicine while $16.7 \%$ found that herbal medicine is more accessible without Doctor's prescription. In total, $15 \%$ of the women found that herbal medicine acts faster than conventional medicine in some conditions. The findings revealed that $5 \%$ of the women preferred the use of herbal medicine for some conditions during pregnancy. In total no-respondent was aware of any birth defect(s) associated with the use herbal medicine during pregnancy. 
Table1: Age Distribution

\begin{tabular}{ccc}
\hline Age & Frequency & Percentage \\
\hline $17-30$ & 176 & 59.7 \\
$30-40$ & 90 & 30.0 \\
$40-40$ & 30 & 10.0 \\
$50-60$ & 1 & 1.0 \\
\hline
\end{tabular}

Table 2: Trimester of herbal medicinal use

\begin{tabular}{lcc}
\hline Trimester & Frequency & Percentage \\
\hline First & 90 & 30.0 \\
Second & 56 & 18.6 \\
Third & 12 & 4.0 \\
None & 142 & 47.3 \\
\hline
\end{tabular}

Table 3: Herbal Medicines used During Pregnancy in Jos North and Jos South LGA's

\begin{tabular}{llllll}
\hline S/N & Plants & Family & Local Names & Common Names & Parts Used \\
\hline 1 & Allium sativum & Liliaceae & Tafarnuwa (Hausa) & Garlic & Bulb \\
2 & Zingiber offincinale & Zingiberaceae & Chetta (Hausa) & Ginger & Rhizome \\
3 & Carica papaya & Caricaceae & Gwanda (Hausa) & Pawpaw & Fruits \\
4 & Mangifera indica & Anacardiaceae & Mangoro (Hausa) & Mango & Fruits \\
5 & Azadiratcha indica & Meliaceae & Dogonyaro (Hausa) & Neem & Leaves \\
6 & Moringa oleifera & Moringaceae & Zogale (Hausa) & Moringa & Leaves \\
7 & Psidum guajava & Myrtaceae & Goba (Hausa) & Guava & Fruit \\
8 & Ocimum gratissimum & Labiaceae & Efirin (Yoruba) & Scent leaf & Leaves \\
9 & Mentha piperita & Lamiaceae & Ewe (Yoruba) & Peppermint & Leaves \\
\hline
\end{tabular}

Table 4. Plants and their indication for use

\begin{tabular}{lccll}
\hline Herbal medicine & Frequency & Percentage & Part used & \multicolumn{1}{c}{ Indication for Use } \\
\hline Garlic & 50 & 16.7 & Bulb & For increasing immunity \\
Ginger & 39 & 13.0 & Rhizome & Nausea \\
Pawpaw & 41 & 13.6 & Fruit & Morning sickness \\
Peppermint & 4 & 1.3 & Leaves & Help relieve stress and anxiety \\
Scent leaves & 9 & 3.0 & Leaves & Stomach discomfort \\
Guava & 1 & 0.3 & Fruits & Prevent gestation diabetes \\
Moringa & 24 & 8.0 & Leaves & Help in breast milk production \\
Neem plant & 2 & 0.6 & Leaves & Reduces stretch mark \\
Mango & 1 & 0.3 & Fruit & Source of energy \\
None & 129 & 43.0 & --- & --- \\
\hline
\end{tabular}

Table 5: Parts of Plant Used

\begin{tabular}{lcc}
\hline Part Used & Frequency & Percentage \\
\hline Leaves & 39 & 13.0 \\
Fruits & 42 & 14.0 \\
Rhizome & 39 & 13.0 \\
Bulb & 50 & 16.7 \\
\hline
\end{tabular}

\section{DISCUSSION:}

The current study revealed that herbal medicine is used among women during their pregnancy. As compared with a study on prevalence of herbal medicine use among pregnant women from the Middle East which varied from $22.3 \%$ to $82.3 \%$ [11]. Most women in the studies were farmers $(33.3 \%)$, housewives $(26.7 \%)$, students $(23.3 \%)$ and civil servant of which their educational level was not above secondary school. These demographics have no impact on the use of herbal medicine. In Mali, a study found that maternal demographic characteristics were not 
associated with use of medicinal plants in pregnancy [12]. Commonly used herbs were ginger, garlic, pawpaw, scent leaves, guava leaves, Moringa, mango leaves and peppermint. On the other hand the herbs most commonly used in Australia, Norway, and Tuscany were raspberry, fennel, and St. John's Wort [8].

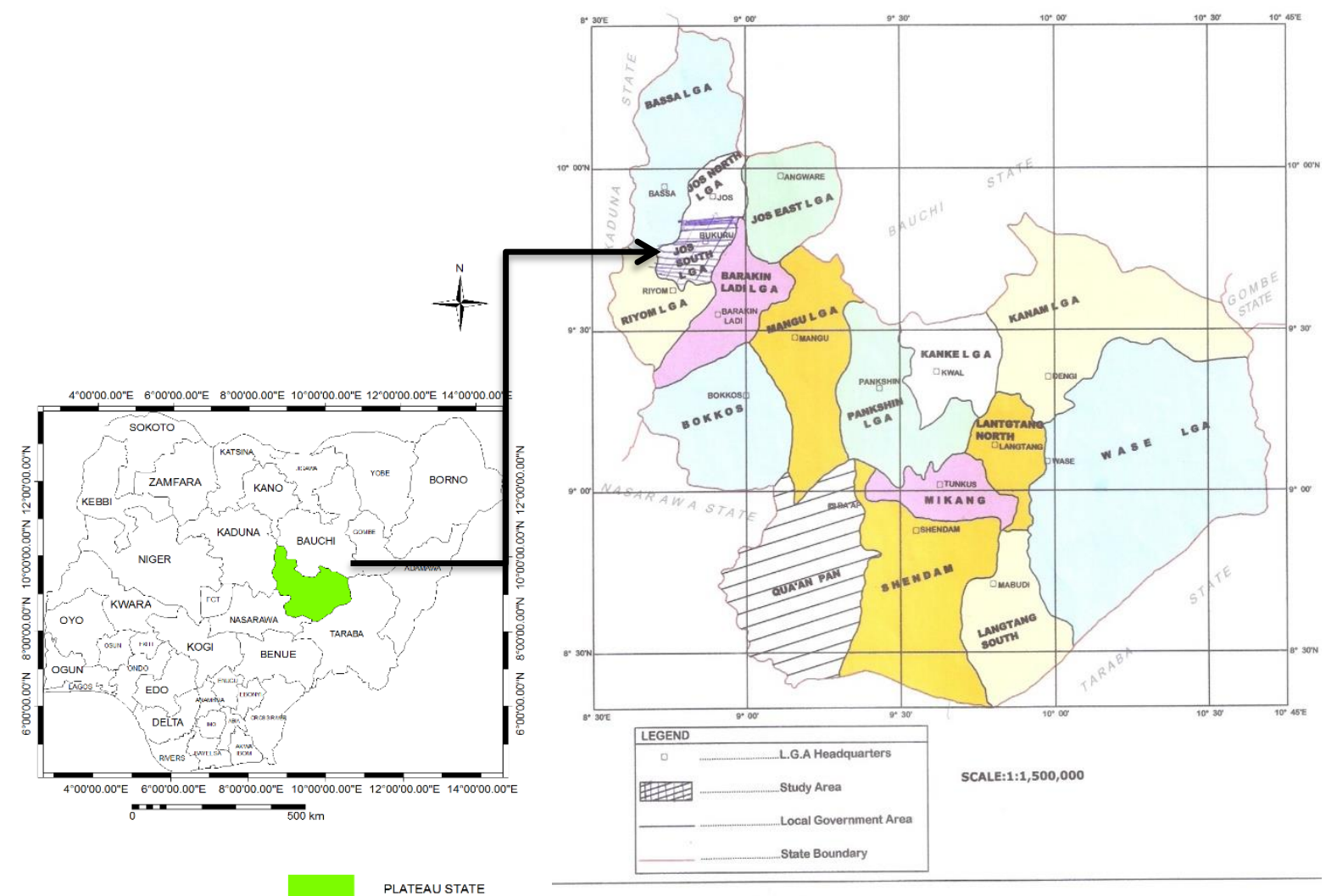

Source: Cartographic Section Ministry of Land Survey and Town Planning, Jos

Figure 1: Map of Plateau State in Nigeria and the study area

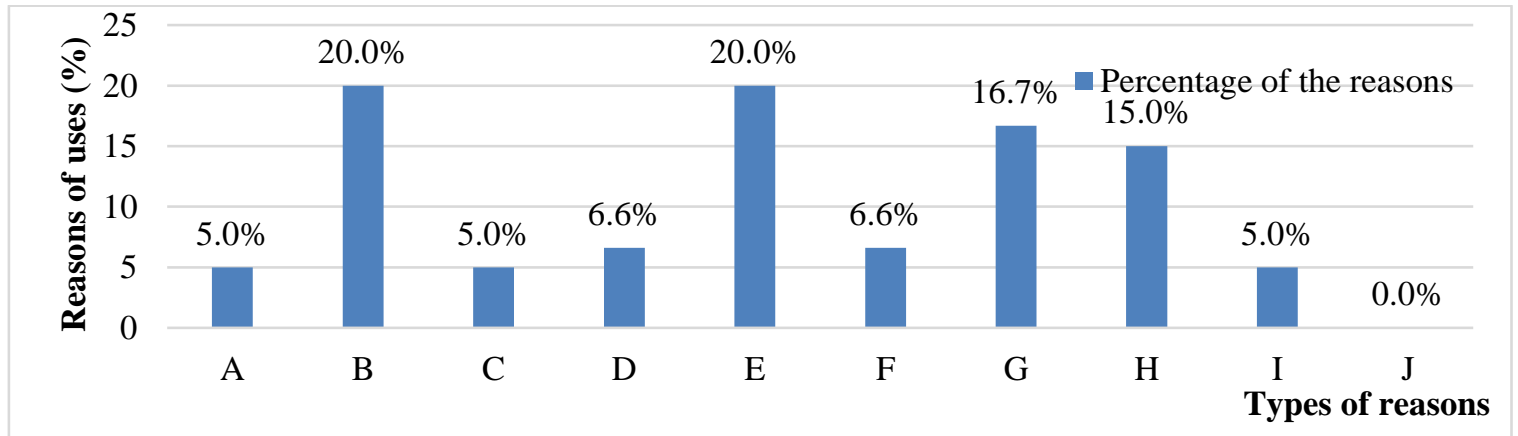

Figure 2: Reasons for Use of Herbal Medicine During Pregnancy

$\mathbf{A}=$ More Effective than Conventional Medicine; $\mathbf{B}=$ More Effective than Conventional Medicine for some Medications; $\mathbf{C}=$ Herbal Medicine together with Conventional Medicine more effective; $\mathbf{D}=$ Herbal Medicine has fewer side effects than Conventional Medicine; $\mathbf{E}=$ Herbal Medicine is easily accessed than Conventional Medicine; $\mathbf{F}=$ Herbal Medicine is less expensive than Conventional Medicine ; $\mathbf{G}=$ Herbal Medicine is more accessible without Doctor's prescription; $\mathbf{H}=$ Herbal Medicine effects faster than Conventional Medicine in some conditions; $\mathbf{I}=$ Prefer the use of Herbal Medicine for some conditions during pregnancy. $\mathbf{J}=$ Not aware of any birth defect(s) associated with the use Herbal Medicine during Pregnancy 
D.G. Dafam et al. / J. Pharmacy \& Bioresources 18(1), 64-73 (2021)

Table 6. Conditions for Taking Herbal Medicines

\begin{tabular}{lccll}
\hline Condition & Frequency & Percentage & Plant Recipes & Herbal Medicine Use \\
\hline Pain & 11 & 3.6 & Blended & Ginger \\
Stretch mark & 24 & 8.0 & Paste & Neem plant \\
Cold and flu & 36 & 12.0 & Blended & Ginger and garlic \\
Morning sickness & 26 & 8.6 & Fruit & Pawpaw \\
Stomach discomfort & 13 & 4.3 & Tea & Scent leaves \\
Headache & 2 & 0.6 & Tea & Scent leaves \\
Immunity & 9 & 3.0 & Bulb & Garlic \\
Blood pressure control & 4 & 1.3 & Bulb & Garlic \\
None & 175 & 58.3 & --- & --- \\
\hline
\end{tabular}

Table 7: Active Constituents of the Herbs Used

\begin{tabular}{lll}
\hline Herbal Medicine & \multicolumn{1}{c}{ Indications for Use } & \multicolumn{1}{c}{ Active Constituents } \\
\hline Ginger & Nausea and vomiting & Gingerols and shogaols [29] \\
Garlic & Increase immunity & Alliin [30] \\
Pawpaw & Morning sickness & Molic acid, Vit. C, Riboflavin [23] \\
Mango & Source of energy & Vit. A, B6 \& C, Folic acid, iron [6] \\
Neem & Stretch mark reduction & Azadirachtin [31] \\
Moringa & Breast milk production & Zinc, protein, calcium, iron [32] \\
Guava & Prevent gestational diabetes & Calcium, phosphorus, Vit. A \& C [31] \\
Scent leaf & Stomach discomfort & Boron and Anetol compounds, Eugenol [33] \\
Peppermint & Relieve stress and anxiety & Menthol and Menthone [12] \\
\hline
\end{tabular}

Table 8: Recommendation/Informants on the Use of Herbal Medicine

SEX: Female

\begin{tabular}{lcc}
\hline Recommendation & Frequency & Percentage \\
\hline Family & 94 & 31.3 \\
Other pregnant women & 80 & 26.7 \\
Pharmacist & 3 & 1.0 \\
None & 123 & 41.0 \\
\hline
\end{tabular}

\section{APPENDIX \\ QUESTIONAIRE USED FOR THE SURVEY \\ DEMOGRAPHIC DATA}

AGE: (a) 17-30 (b) 30-40 (c) 40-50 (d) 50-60.

OCCUPATION: (a) Student (B) Farmer (C) House wife (D) Civil servant

Others (please specify)

EDUCATIONAL LEVEL: (A) No Formal Education (B) Primary school (C) secondary school (D) Higher Education PARTS AND PATTERN OF HERBAL MEDICINE USE

1. Which herb(s) do you use or have used?

2. Which condition(s) have you used or using the herbal medicine for?

3. How often do you take the herbal medicines?

4. Do you know the part of the plant used for the preparation of the herbal medicines? Please specify

5. Who recommended the herbal medicine?

i. Family/friend

ii. Pharmacist

iii. Other pregnant women

iv. Gynecologist

6. Where did you get the information about the use of herbal medicine from?

I. family/friend

ii. Books/News paper

iii. Internet 
iv. Herbal store

v. Pharmacy

vi. Television

vii. Physician

7. In which trimester do you use the herbal medicine?

i. First

ii. Second

iii. Third

vi. None

REASONS FOR USE OF HERBAL MEDICINE DURING PREGNANCY

\begin{tabular}{|l|l|l|l|l|l|}
\hline & \multicolumn{1}{|l|}{} & NO & YES & $\begin{array}{l}\text { I THINK } \\
\text { SO }\end{array}$ & $\begin{array}{c}\text { I DON'T } \\
\text { KNOW }\end{array}$ \\
\hline 1. & Is herbal medicine more effective than conventional medicine? & & & & \\
\hline 2. & $\begin{array}{l}\text { Is herbal medicine more effective than conventional for some } \\
\text { medications? }\end{array}$ & & & \\
\hline 3. & $\begin{array}{l}\text { Is herbal medicine together with conventional medicines } \\
\text { effective? }\end{array}$ & & & \\
\hline 4. & $\begin{array}{l}\text { Are there fewer side effects with herbal medicine than } \\
\text { conventional medicine? }\end{array}$ & & & \\
\hline 5. & Is herbal medicine easily accessed than conventional medicine? & & & \\
\hline 6. & Less expensive than conventional medicine. & & & \\
\hline 7. & More accessible without doctor's prescription. & & \\
\hline 8. & $\begin{array}{l}\text { In some conditions, herbal medicine effects are faster than } \\
\text { conventional medicine. }\end{array}$ & & & \\
\hline 9. & $\begin{array}{l}\text { Prefer the use of herbal medicine for some conditions during } \\
\text { pregnancy }\end{array}$ & & & \\
\hline 10. & $\begin{array}{l}\text { Are you aware of any birth defect(s) associated with the use of } \\
\text { herbal medicines during pregnancy? If yes please specify }\end{array}$ & & & \\
\hline
\end{tabular}

The use of the herbal products varied with the trimester and associated pregnancyrelated problems. Although herbal products may offer a benefit, it is important to detect even small risk that would significantly affect the risk-benefit ratio in pregnancy. Evidence on efficacy and safety in pregnancy for most of these herbs is limited. A meta-analysis reported that ginger is safe and efficacious in nausea and vomiting during pregnancy [13]. A high incidence of threatened miscarriages and preterm labor have been reported with the use of chamomile and licorice during pregnancy [11]. In a review on the herbs used for morning sickness, chamomile and peppermint were reported as unsafe in $6 \%$ of studies and ginger and raspberry leaf were cited as safe in $12 \%$ and $15 \%$ of the studies, respectively [14]. Excessive use of peppermint is contraindicated in early pregnancy due to its emmenagogue effects [15]. Most of the herbs are safe when used in moderation and excessive consumption can produce unknown effects [16]. For example, although the caffeine content in green tea is $30-60 \%$ less than in coffee, it is recommended to avoid consumption of large quantities due to its interference with various metabolic processes [17]. The fact that these unsafe herbs are among those commonly used is a matter of concern.

The majority of studies reported maximum use of herbs during the first trimester; probably due to the higher incidence of pregnancy-related problems during this period. Most women are unaware that the first trimester is the most critical period of pregnancy when fetal organogenesis occurs and utmost care should be taken to reduce the risk of fetal morbidity and mortality [18]. It is a well-documented fact that the risk in 
pregnancy is unknown for $91.2 \%$ of the approved medications [19]. The use of herbal products which are not usually tested in clinical trials during pregnancy could result in immense risk to the mother and fetus [20].

Since herbal medicine is a part of traditional medicine, they are not part of the FDA (food, drug and administration) pregnancy categories giving a false impression of safety. The extracts of these herbal drugs contain numerous active molecules that could elicit adverse effects including teratogenicity [11]. Moreover, these preparations are sold as unlicensed food supplements or as over-thecounter items, which are not regulated with the same scrutiny as conventional drugs thus increasing the probability of contamination or adulteration with poisonous metals, nondeclared herbs or conventional medicines [21]. Use of herbal medicine concurrently with conventional medications could result in herbdrug interactions and undesirable effects [22]. Due to the widespread use of herbal drugs during pregnancy, there is a need for regulation of these drugs to ensure their safety and determine the efficacy and constituents of the preparations.

Family and other pregnant women were the common referral/information sources in the studies representing 31.3 and $26.7 \%$ respectively which is in agreement with Nergard and coworkers who found that the family and friends were the most represented source of recommendation [12]. There is a high prevalence of use of alternative medicine in the general population and suggestions for its use in pregnancy are typically based on individuals' own experience or of those around them [23]. The scientific rationale in using these medications have to be considered and this insight may be lacking in these cases. The studies reviewed also reported healthcare professionals as the source of information (1.0 $\%)$. In a study from Norway, $80.7 \%$ of the physicians rated their knowledge of herbal drugs to be poor [24]. Therefore, health care professionals should update their knowledge on the efficacy; potential risks, possible herbdrug interactions and consequences, and the key principles applied to the administration of herbs during pregnancy and should also screen their patients for use of herbal medicines [25]. Two studies, one from Iran [26] and another from Palestine [27] reported that $37.8 \%$ and $65.8 \%$ of pregnant women, respectively, informed their physicians about the use of herbal medicines.

Pregnant women need to inform their physician about any herbs used preferably before use. Also physicians should specifically ask about herbs usage and document it in the patient record. Pregnant women should be informed of the potential risks posed by herbs during pregnancy and advised to avoid their use.

Herbal medicines were commonly perceived to be more effective for some conditions, have fewer side effects and more accessible without doctor's prescription than conventional medicines. That is why its use by the population is over $80 \%$, which is in agreement with the reported work of Middle East [11]. Although they are considered safe, in reality it is known that the active ingredients in herbs can cause serious side effect as the quantity consumed is usually not known [11]. Therefore pregnant women should be trained to increase their awareness regarding the effects of herbal medications and the importance of taking guidance from their healthcare providers.

Many countries have not researched into this area of concern. The current work sheds light on the perception about the use of herbal medicine in pregnancy, reasons for use, plant parts used and efficacy of the herbal products used by pregnant women in the treatment of some conditions.

Different studies have shown that many women used one or more herbal medicine during pregnancy. Some women used herbal medicine in first trimester while 
D.G. Dafam et al. / J. Pharmacy \& Bioresources 18(1), 64-73 (2021)

others used it in second trimester or third trimester or throughout pregnancy. The use of herbal medicine during pregnancy is a common phenomenon. However further investigations are needed to demonstrate the safety of the medicinal plants used during pregnancy.

\section{REFERENCES}

1. World Health Organization. Traditional medicine. Geneva. 2008. Available at http://www.who.int/medicines/areas/traditional/en/ . Accessed February 4, 2013.

2. World Health organization. Traditional medicine. Fact sheet number 134. Available form:http://www.who.int/mediacentre/factsheets/fs 134/en/[Accessed:December01, 2017].

3. Banhidy F, Lowry RB, Czeizel AE. (2005). Risk and benefit of drug use during pregnancy. International Journal of Medical Sciences, 2: 1006.

4. Lindzon G, Sadry S, Sharp J. Obstetric. (2011). Toronto Notes for Medical students. $27^{\text {th }}$ Edition. Type \& Graphics Inc. Canada.

5. John LJ, Shantakumari N. (2015). Herbal Medicines Use During Pregnancy: A Review from the Middle East. Oman Medical Journal, 30(4): 229-236.

6. Kennedy DA, Lupattelli A, Koren G, Nordeng H. (2016). Safety classification of herbal medicines used in pregnancy in a multinational study. $B M C$ Complementary and Alternative Medicine, 16: 102.

7. Kennedy DA, Lupattelli A, Koren G, Nordeng H. (2013). Herbal medicine use in pregnancy: results of a multinational study. BMC Complement Alternative Medicine, 13: 355.

8. Forster DA, Denning A, Wills G, Bolger M, McCarthy E. (2006). Herbal medicine use during pregnancy in a group of Australian women. BMC pregnancy and childbirth, 6(1): 21.

9. Mothupi MC. (2014). Use of herbal medicine during pregnancy among women with access to public healthcare in Nairobi, Kenya: a crosssectional survey. BMC Complementary and Alternative Medicine, 14: 432.

10. Fakeye TO, Adisa R, Musa IE. (2009). Attitude and use of herbal medicines among pregnant women in Nigeria. BMC Complementary and Alternative Medicine, 9: 53.
11. Cuzzolin L, Benoni G. (2009). Safety issues of phytomedicines in pregnancy and paediatrics. In Herbal drugs: ethnomedicine to modern medicine. pp. 381-396. Springer, Berlin, Heidelberg.

12. Nergard CS, Ho TP, Diallo D, Ballo N, Paulsen BS, Nordeng H. (2015). Attitudes and use of medicinal plants during pregnancy among women at health care centres in three regions of Mali, West-Africa. Journal of ethnobiology and ethnomedicine, 11(1): 73.

13. Moradi Lakeh M, Taleb AM, Saeidi MA. (2008). Efficacy and safety of ginger to reduce nausea and vomiting of pregnancy: a systematic review and meta-analysis. Payesh (Health Monitor), 7(4): 34554.

14. Wilkson JM. (2000). What we know about herbal morning sickness treatment? A literature survey. Midwifery, 16: 224-228.

15. Fleming T. (2009). PDR for herbal medicines. $4^{\text {th }}$ ed. Thomson health care Inc. USA. pp: 121,414, 522,649 .

16. Orief YI, Farghaly NF, Ibrahim MI. (2014). Use of herbal medicines among pregnant women attending family health centres in Alexandria. Middle East Fertility Society Journal, 19(1): 42-50.

17. Kee JL, Hayes ER, McCuistion LE. (2014). Pharmacology: A Patient-Centered Nursing Process Approach. $8^{\text {th }}$ Edition. Elsevier Health Sciences. p.61-78.

18. Marcus DM, Snodgrass WR. (2005). Do no harm: avoidance of herbal medicines during pregnancy. Obstetrics \& Gynecology, 105(5): 1119-22.

19. Aasland OG, Borchgrevink CF, Fugelli P. (1997). Norwegian physicians and alternative medicine. Knowledge, attitudes and experiences. Tidsskr Nor Laegeforen, 117(17): 2464-2468.

20. Holst L, Wright D, Haavik S, Nordeng H. (2011). Safety and efficacy of herbal remedies in obstetrics-review and clinical implications. Midwifery, 27(1): 80-6.

21. Elolemy AT, AlBedah AM. (2012). Public knowledge, attitude and practice of complementary and alternative medicine in Riyadh region, Saudi Arabia. Oman medical journal, 27(1): 20.

22. Thomas K, Coleman P. (2004). Use of complementary or alternative medicine in a general population in Great Britain. Results from the National Omnibus survey. Journal of Public Health, 26(2): 152-7. 
23. Duraz AY, Khan SA. (2011). Knowledge, attitudes and awareness of community pharmacists towards the use of herbal medicines in Muscat region. Oman medical journal, 26(6): 451.

24. Hashem DF, Fard MA, Shojaei A, Kianbakht S, Zafarghandi N, Goushegir A. (2012). Use And Attitude on Herbal Medicine in a group of Pregnant Woman in Tehran. Journal of Medicinal Plants, 11(41): 22-33.

25. Adawi DH. (2012). Prevalence and Predictors of Herb Use during Pregnancy (A study at Rafiia Governmental Hospital/Palestine).
26. Ozgoli G, Goli M, Simbar M. (2009). Effects of ginger capsules on pregnancy, nausea, and vomiting. The Journal of Alternative and Complementary Medicine, 15(3):243-6.

27. Charlson M, McFerren M. (2007). Garlic: What we know and what we don't know. Archives of internal medicine, 167(4):325-6.

28. Jellin JM, Gregory P, Batz F, Hichens K. (2001). Pharmacist's Letter/Prescriber's Letter Natural Medicines Comprehensive Database, Stockton, CA. 